\title{
ATUAÇÃO DA ENFERMAGEM FORENSE SOB A ÓPTICA DE ESTUDANTES DE GRADUAÇÃO EM ENFERMAGEM
}

\author{
PERFORMANCE OF FORENSIC NURSING FROM THE PERSPECTIVE OF \\ UNDERGRADUATE NURSING STUDENTS
}

\author{
Igor de Oliveira Reis ${ }^{1} *$ Natália Rayanne Souza Castro ${ }^{2} *$ Mônica Chaves $^{3} *$ Jhuliano Silva $^{*}$ \\ ${\text { Ramos de } \operatorname{Souza}^{4} * \text { Lilian de Oliveira Corrêa }}^{5}$
}

\begin{abstract}
RESUMO
Objetivo: analisar a visão de estudantes do curso de enfermagem acerca da atuação da Enfermagem Forense. Método: estudo qualitativo, descritivo e exploratório, realizado com 10 estudantes de enfermagem de uma universidade privada da região norte do Brasil. Foi utilizada uma entrevista semiestruturada, por meio da adaptação do instrumento denominado: Questionário de Conhecimentos sobre Práticas de Enfermagem Forense. Para categorização das falas utilizou-se a Análise de Conteúdo. Resultados: os particantes identificaram a enfermagem forense por meio de algumas habilidades e competências, bem como seu campo de atuação, assistência à pacientes forenses e protocolos instituicionais. Conclusão: foi possível compreender como os estudantes de enfermagem relacionaram a enfermagem forense como campo de atuação, trazendo limitações do conhecimento relacionados ao conceito da especialidade e as especificidades de atuação, com ênfase na abordagem e cuidado às pessoas em situação de violência e os procedimentos técnicos no manejo de vestígios.
\end{abstract}

Palavras-chave: Enfermagem Forense; Estudantes de Enfermagem; Violência; Educação Superior.

\begin{abstract}
Objective: to analyze the view of nursing students about the role of Forensic Nursing. Method: qualitative, descriptive and exploratory study, conducted with 10 nursing students from a private university in northern region of Brazil. A semi-structured interview was used, through the adaptation of the instrument called: Questionnaire of Knowledge on Forensic Nursing Practices. To categorize the statements, Content Analysis was used. Results: participants identified forensic nursing through some skills and competencies, as well as their field of work, assistance to forensic patients and institutional protocols. Conclusion: it was possible to understand how nursing students related forensic nursing as a field of action, bringing limitations of knowledge related to the concept of the specialty and the specificities of performance, with an emphasis on approaching and caring for people in situations of violence and technical procedures in the management of traces.
\end{abstract}

Keyword: Forensic Nursing; Nursing students; Violence; College education.

\footnotetext{
${ }^{1}$ Enfermeiro pela Faculdade Estácio do Amazonas (2020). Integrante do Grupo de Estudos e Pesquisas em Enfermagem Forense da Universidade Federal da Paraíba (GEPEFO/UFPB) e do Grupo de Pesquisa: Políticas Públicas, Gestão, Qualidade e Inovação em Saúde, da Fundação Hospital Adriano Jorge (FHAJ), ambos cadastrados no CNPq. Orcid: https://orcid.org/0000-0002-9834-5538. Email: https://orcid.org/0000-0002-9834-5538

${ }^{2}$ Graduanda do curso de Enfermagem na Escola de Enfermagem de Manaus (EEM) da Universidade Federal do Amazonas (UFAM). Secretária Adjunta do Centro Acadêmico do Curso de Enfermagem - CACEn da EEM/UFAM (2019-2020). Membro fundador e secretária geral da Liga Amazonense de Sistematização da Assistência de Enfermagem - LAMSAE (2017-2020) e diretora geral da. Orcid: https://orcid.org/0000-0002-9164-3428. Email: nataliarayannesc@ gmail.com

${ }^{3}$ Enfermeira pela Pontifícia Universidade Católica de Minas Gerais. Mestre em Enfermagem pela Universidade Federal de Minas Gerais. Especialista em Enfermagem do Trabalho e em Enfermagem na Assistência ao Portador de Lesões Cutâneas pelo Instituto de Educação Continuada da PUC-Minas. É Membro do grupo de Pesquisa Processos Heurísticos e Assistência em Saúde e Enfermagem - PHASE no Curso de Enfermagem da PUC Minas (Betim) e GEPIVE- Grupo de Estudos Interdisciplinares em Cuidados Paliativos na PUC Minas Betim. Orcid: https://orcid.org/0000-0002-5026-6558 Email: monikachaves@ uol.com.br

${ }^{4}$ Enfermeiro pela Universidade do José Rosário Vellano. Mestre em Enfermagem pelo Programa de Pós-Graduação em Enfermagem da Universidade Federal de Alfenas, como bolsista da Coordenação de Aperfeiçoamento de Pessoal de Nível Superior (CAPES). Doutorando em Enfermagem pelo Programa de Pós-Graduação em Enfermagem da Universidade Federal de Alfenas. Pós-Graduando em Enfermagem Psiquiátrica e Saúde Mental pela Faculdade de Venda Nova do Imigrante. Membro do Grupo de Pesquisa do CNPq "Tecnologias, Inovações e Sustentabilidade em Saúde" da Universidade Federal de Alfenas (UNIFAL-MG. Orcid: https://orcid.org/0000-0002-4338-4433 Email: jhulianoramoz@ hotmail.com

${ }^{5}$ Enfermeira e Bióloga. Doutora em Enfermagem pelo DINTER (Universidade do Estado do Amazonas e Universidade Federal de Santa Catarina-UEA-UFSC). Mestre em Biotecnologia e Recursos Naturais da Amazônia pela Universidade do Estado do Amazonas. Especialista em Biotecnologia e Especialista em Urgência e Emergência. Graduação em Ciências Biológicas pela Universidade Federal de Uberlândia, e Graduação em Enfermagem pela Universidade Federal do Amazonas. Docente do curso de enfermagem da Universidade do Estado do Amazonas (UEA) e da Faculdade Estácio Amazonas. Coordenadora do Programa de Residencia em Enfermagem em Urgência. Orcid: https://orcid.org/0000-0002-0788-6786 Email: $\underline{\text { liliancoroli@ yahoo.com.br }}$
} 


\section{INTRODUÇÃO}

A Enfermagem Forense (EF) é definida como a aplicação do saber científico e técnico da área de enfermagem às situações clínicas consideradas forenses, pressupondo o cruzamento entre o sistema de saúde e o jurídico, no qual presta cuidados diretos às vítimas, ofensores e a todos que testemunham situações de violência ${ }^{(1-2)}$.

No Brasil, a EF é reconhecida como uma especialidade desde $2011^{(3)}$. Em $2017^{(4)}$, o Conselho Federal de Enfermagem (COFEN) aprovou a resolução de atuação do enfermeiro forense, que assenta a resposta aos problemas de saúde decorrentes de trauma e/ou toda e qualquer forma de violência, como na identificação, coleta e preservação de vestígios forenses, tratamento a casos de Violência por Parceiro Íntimo, maus-tratos, abuso sexual e negligência de crianças e idosos, agressão sexual, investigação da morte e cuidados com pessoas encarceradas.

A Organização Mundial da Saúde enfatiza a responsabilidade das instituições competentes quando se fala em violência, pois se constitui como um grave problema de saúde pública, o qual requer a participação dos profissionais da saúde, entre eles o enfermeiro, pois este exerce função essencial na prevenção e restabelecimento da saúde da população ${ }^{(1-5)}$. O atual cenário da violência no Brasil teve um aumento em decorrência das causas de morte, sendo elas externas e naturais, em que as principais vítimas são crianças, jovens e idosos do sexo masculino e feminino $^{(6)}$.

Nesse contexto, vivencia-se uma realidade que está longe de ser o ideal, pois os enfermeiros têm experiência na prestação de cuidados numa perspectiva física e psicológica do paciente, mas a maioria não está preparado para identificar e cuidar das pessoas em situação de violência e determinar com exatidão que evidências devem ser colhidas e preservadas de acordo com os princípios forenses $^{(7)}$.

Neste caso, é necessário discutir sobre a EF no âmbito acadêmico, pois considerando que os enfermeiros convivem com o problema cotidianamente nos serviços de saúde, entende-se que a enfermagem precisa ter conhecimento sobre a temática em estudo e estabelecer no seu processo de trabalho a dimensão cuidadosa na perspectiva do cuidado individual e coletivo, buscando responder aos desafios de compreender melhor o processo da violência e formar profissionais competentes e socialmente comprometidos no seu enfrentamento ${ }^{(1)}$.

Diante disso, para conduzir a pesquisa formulou-se a seguinte questão: como os estudantes de enfermagem veem a EF e seus campos de atuação? Portanto, o objetivo desse estudo foi analisar a visão de estudantes do curso de enfermagem acerca da atuação Enfermagem Forense. 


\section{MÉTODO}

Trata-se de um estudo descritivoexploratório, com abordagem qualitativa, realizado com acadêmicos finalistas do curso de graduação em enfermagem de uma Instituição de Ensino Superior (IES) privada em Manaus, Amazonas. Os critérios de inclusão foram alunos devidamente matriculados no $10^{\circ}$ período, visto que estes se encontravam na condição de finalistas do curso e teoricamente passaram por todos os semestres, sendo indivíduos aptos à responderem os questionamentos do objeto de estudo. Os de exclusão foram aqueles afastados da universidade por trancamento de matrícula, discentes em período de estágio currícular, e os que estavam trabalhando no momento da coleta de dados.

$\mathrm{O}$ instrumento utilizado foi $\mathrm{o}$ Questionário de Conhecimentos sobre Práticas de Enfermagem Forense (QCPEF), de origem europeia $^{(7)}$ e da versão traduzida e validada para a cultura brasileira $^{(8)}$, que consiste em questões sociodemográficas, acadêmicas e de formação em EF, que incluiu 74 afirmações dicotômicas (verdadeiras ou falsas) e objetiva avaliar o conhecimento do conceito de EF; situações forenses; vestígios forenses; comunicação e documentação de evidências e cuidado na preservação de vestígios.

Diante disso, os autores que elaboraram, traduziram e validaram $\mathrm{o}$ QCPEF, autorizaram que os pesquisadores deste estudo o adaptassem para uma abordagem qualitativa, por meio da categorização do conjunto de ítens do instrumento por perguntas abertas em formato de entrevista semiestruturada, que foram realizadas entre fevereiro e março de 2020. Estas aconteceram em uma sala fechada da coordenação do curso, com o minímo de ruídos ou barulhos externos que pudessem atrapalhar a compreenssão do pesquisador e dos participantes, sendo utilizado um gravador digital para posteriormente auxiliar na transcrição dos discursos.

Para a categorização das falas, utilizou-se a Análise de Conteúdo ${ }^{(9)}$, sendo dividida em três etapas. A primeira compreendeu-se na transcrição das falas e organização das ideias iniciais, no qual ocorreu à leitura flutuante como forma de aproximação do pesquisador com as fontes analisadas. Em seguida, o material foi explorado consistindo na efetivação sistemática das informações colhidas e execução dos recortes representativos dos discursos. Por fim, os resultados obtidos foram tratados e interpretados categoricamente.

O estudo teve aprovação do Comitê de Ética em Pesquisa sob $\mathrm{o}$ parecer $\mathrm{n}^{\mathrm{o}}$ 3.372.745/2019, seguindo a Resolução 466/2012 do Conselho Nacional de Saúde em https://doi.org/10.31011/reaid-2021-v.95-n.34-art.997 Rev Enferm Atual In Derme v. 95, n. 34, 2021 e-021058 
que os participantes assinaram o Termo de Consentimento Livre e Esclarecido, o qual reservou o anonimato dos participantes, substituindo seus nomes por: AL1, AL2, AL3, assim sucessivamente.

\section{RESULTADOS E DISCUSSÃO}

Antes de analisar os resultados e discuti-los, foram traçadas as características sociodemográficas dos sujeitos participantes do estudo. Dos dez alunos, oito eram do sexo feminino e dois do sexo masculino, com idade média de 27 anos, naturais dos municípios de Manaus-AM (5), Nhamundá-AM (1), Autazes-AM (1), Barreirinha-AM (1), Boa Vista-RR (1) e Óbidos-PA (1), localizados na região Norte do Brasil.

A partir da categoria proposta: Conceito e atuação da Enfermagem Forense, elencaram-se subcategorias que permitiram compreender por meio da fala dos estudantes a prática profissional relacionada a identificação, coleta e preservação de vestígios, como também a conduta ética e documentação na assistência à pacientes forenses.

\section{Conceito e atuação da Enfermagem Forense na visão dos graduandos de enfermagem}

No que tange ao conceito de EF, observou-se que os participantes consideram uma área que estuda a parte criminal e investigativa, envolvendo questões em estudo de assassinatos, acidentes, assistência às vítimas de violência, correlacionando a enfermagem e o Instituto Médico Legal (IML) e a participação em conjunto com a polícia.

Estuda a parte criminal que o enfermeiro pode atuar e casos especificos também, 'né!?'. (AL 1)

É a questão do papel investigativo da enfermagem, sobre o que a enfermagem pode fazer no campo da investigação criminal, por exemplo, assassinatos, acidentes, questão de andar com a enfermagem no IML, participando em conjunto com a polícia, fazendo um papel mais investigativo. (AL 2)

Meu conhecimento não é tão amplo, mas a forense abrange áreas que envolvem questão de óbitos. (AL 3)

Acho que é responsável por prestar assistência às vítimas de violência. (AL 7)

Apesar dos discentes reconhecerem alguns pontos importantes da especialidade, como a assistência à pessoas em situação de violência e a contribuição no processo investigativo, os relatos demonstram uma visão reducionista sobre a $\mathrm{EF}$, em que os 
sujeitos mostraram um conhecimento limitado sobre o conceito.

Para diferenciar a EF de outras especialidades da profissão, é necessário compreender que ela está interligada com a ciência de enfermagem e a prática forense, afim de promover cuidados diretos às vítimas, aos perpetradores e aos familiares ${ }^{(2)}$. É uma especialidade da enfermagem com subespecialidades que se concentram na prática clínica forense, prestando assistência a pacientes vivos e falecidos na interface jurídica e clínica ${ }^{(1)}$. Do mesmo modo, ela pode ser definida como uma prática clinica no atendimento a pessoas em situação de violência, numa abordagem investigativa e criminal, em que o enfermeiro irá prestar seus cuidados à essas vítimas ${ }^{(7)}$.

Quanto aos domínios e campos de atuação da EF, os participantes citaram áreas e disciplinas como a perícia, a necropsia, a autópsia, a saúde mental, a saúde coletiva e os grandes desastres, como atuações do enfermeiro em situações forenses.

Atuação da enfermagem em saúde mental, saúde coletiva. (AL 4)

Pode ajudar na investigação da causa da morte no processo de autópsia e preparar o corpo para ser examinado. (AL 5)

A perícia em si faz parte da enfermagem forense. (AL 9)
Atuar nos grandes desastres. (AL 10)

Os participantes mencionam a $\mathrm{EF}$ de forma abrangente, por meio da interdisciplinaridade das áreas citadas, o que tendem a não distinguir a atuação de cada profissional na dinâmica de trabalho, ainda mais se tratando da $\mathrm{EF}$, por ser relativamente uma especialidade nova na enfermagem.

$\mathrm{Na}$ atuação em saúde mental, citada pelo AL4, têm-se o domínio Enfermagem Psiquiátrica Forense, que desenvolve cuidados às pessoas privadas de liberdade ou sob custódia legal, numa abordagem interdisciplinar nas tomadas de decisão com o sistema judicial. Também desenvolve sua prática clínica às vítimas afim de auxiliá-las no restabelecimento da saúde mental e reintegração social, prestando cuidados dentro do sistema penitenciário(10-11).

Já no processo de Investigação da Morte, sendo ela violenta (suicídio, homicídio e acidente) ou natural (doença), o enfermeiro forense presta assistência biopsicossocial aos sobreviventes e aos familiares enlutados em qualquer etapa do ciclo vital. Ressalta-se que no post mortem, a realização do exame de necropsia/autópsia pode ser auxiliada por um enfermeiro com expertise na área ${ }^{(12)}$.

Os Grandes desastres ou Desastres em massa, mencionado como um dos campos de atuação da EF, é um dos domínios em que 
enfermeiro forense estabelece respostas humanas aos processos de vida das pessoas em cenário de desastres, quer seja de causa natural ou por intervenção humana ${ }^{(4)}$. $\mathrm{O}$ fenômeno da violência está diretamente relacionado à episódios catastróficos, em que a equipe de enfermagem de modo geral, precisa está preparada para prestar cuidados referente a esses casos que envolvem múltiplas vítimas ${ }^{(13)}$.

Em uma das falas dos participantes da pesquisa, foi mencionado que a EF está relacionada com a atuação pericial, sendo importante destacar que são atribuições distintas que se complementam no processo de trabalho. O serviço dos peritos começa na cena do delito com o reconhecimento dos vestígios e materiais, prossegue com a análise e a avaliação dos resultados obtidos em laboratório e apresentação de suas conclusões no tribunal ${ }^{(14)}$. É necessário frisar que o enfermeiro, sendo forense ou não, pode tornase um períto judicial, sendo um auxílio para justiça nos processos investigativos, como por exemplo, na prestação de depoimentos ${ }^{(4)}$.

Para o aprofundamento da visão dos alunos sobre a atuação da EF em casos específicos, seguem-se as duas subcategorias elencadas: Identificação, coleta e preservação de vestígios forenses; e, Ética e documentação na assistência à pacientes forenses.

\section{- Identificação, coleta e preservação de vestígios forenses}

Nesta primeira subcategoria, os participantes relataram que os vestígios forenses estão interligados numa perspectiva criminal, em que o profissional especialista irá auxiliar nesse processo investigativo. Ainda em relação aos vestígios, observou-se uma vasta limitação de conhecimento dos estudantes sobre esses conteúdos referente à prática forense.

Os vestígios seriam os restos de um crime, então não faço ideia como proceder, mas ouço muito no jornal. (AL 1)

É tudo que está relacionado a investigação da morte, como digitais, cabelo, roupa, sangue, tudo que a pessoa poderia deixar no momento do crime. (AL 2)

Não sei os procedimentos técnicos, mas sei que são materiais utilizados para entender como é que foi a morte, para estudar tanto na pessoa quanto na questão do ambiente, como foi $o$ assassinato. (AL 3)

Não sei nada sobre vestígios. (AL 4)

Não tenho conhecimento detalhado de causa, mas são recursos para analisar um crime de agressão sexual, por exemplo. (AL 6) 
Sei que é um período muito curto para analisar as pistas, aquilo que é deixado justamente para enriquecer o trabalho da perícia, como as impressões digitais, a marca do tênis, a impressão que ficou na faca, fio de cabelo, botão, tudo que se refere ao momento do crime. (AL 9)

Os vestígios são de suma importância em qualquer investigação criminal, pois contribuem para a resolução dos casos judiciais, por relacionarem de forma simultânea o local do crime, a vítima e o infrator. Eles podem ser sinais, traços, manchas ou objetos que são deixados por um indivíduo suspeito de algum delito, permitindo aos serviços da polícia científica investigar as evidências que possam comprovar o crime e a sua autoria ${ }^{(15)}$.

Existem três classificassões para os vestígios forenses, sendo eles lofoscópicos, biológicos e fisico-químicos. Os lofoscópicos se referem à impressões digitais, impressões palmares e plantares. Os biológicos são tudo aquilo relacionado à sangue, sémen, saliva, cabelo, ossadas, dentes, pelos, placenta, DNA e secreções vaginais. Já os físico-químicos são pegadas, rastos de pneus, projéteis, armas brancas, armas de fogo, objetos ou instrumentos cortantes e perfurantes ${ }^{(16)}$.

No que se refere ao atendimento das pessoas em situação de violência, o serviço de
Urgência e Emergência é a principal porta de entrada dessas vítimas, em que os enfermeiros são os primeiros responsáveis pela elaboração da triagem, implementação e organização dos cuidados e tratamentos clínicos dos utentes destes serviços. Por essa grande demanda, muitos acabam desprezando vestígios importantes, como roupas e acessórios, que poderiam auxiliar posteriormente na elucidação de casos de morte violenta, que entre os mais frequentes são os acidentes de trânsito e as tentativas de homicídio ${ }^{(13-15)}$.

$\mathrm{Na}$ coleta e preservação de vestígios nos casos de violência física e sexual, todas as peças de vestuário interior e exterior deverão ser cuidadosamente removidas e embaladas separadamente em sacos ou pacotes de papel, nunca em recipientes de plástico. $\mathrm{O}$ enfermeiro deverá recolher cada item assim que a vítima se despir procedendo, posteriormente, ao seu empacotamento, de forma a evitar a contaminação cruzada das evidências físicas, e em seguida, a folha de papel deverá ser dobrada, passível de ser analisado a nível laboratorial ${ }^{(1-7)}$.

Pela complexidade nesses casos e em outras formas de violência, é imperioso que estudantes de enfermagem ainda na graduação conheçam as técnicas de identificação, coleta e preservação de vestígios, pois os serviços de saúde que demandam situações nesse nível, precisam que enfermeiros estejam preparados em uma atuação técnico-científica detalhada 
no cuidado integral e qualificado, de acordo com os princípios forenses.

Para os profissionais que já atuam, a busca do conhecimento é necessária nesta vertente para aplica-la em sua prática assistencial. O desconhecimento nesses casos prejudica posteriormente o trabalho da perícia médico-legal, sendo o enfermeiro o profissional que poderia se tornar mediador entre o paciente e a justiça, pois seu olhar mais atento e sagaz aos sinais físicos e comportamentais contribuem efetivamente para punição do agressor e no cessar da violência $^{(14)}$.

\section{- Ética e documentação na assistência à pacientes forenses}

Nesta subcategoria, os discentes destacaram o sigilo, o controle emocional, a humanização, o trabalho multidisciplinar e o encaminhamento à serviços especializados, como cuidados prestados às pessoas em situação forense, principalmente em casos de violência sexual. Além disso, frisaram a importância do registro de enfermagem como respaldo.

Os profissionais precisam ser éticos e responsáveis, documentar tudo para está respaldado. (AL 1)

Tem que ser sigiloso e nos envolver o mínimo emocional possivel. (AL 2)

Acho que existem protocolos de atendimento as vítimas de violência, principalmente sexual, então os profissionais especializados têm que conhecer essas documentações, e o próprio POP da instituição pode ter informações detalhadas de conduta. (AL 5)

Eu acolheria e posteriormente notificaria outros profissionais que contribuiriam com o atendimento. (AL 7)

Acho que é necessário exercer de forma correta essa questão de legislação e documentação, atentando principalmente para parte hierárquica da instituição no qual esse profissional trabalha. (AL 9)

É preciso conversar com a paciente para saber a situação. Acionar o serviço social, e a polícia se possível. (AL 10)

$\mathrm{Na}$ assistência à pacientes forenses, uma série de questões precisam ser levadas em consideração, entre elas a maneira em que o enfermeiro irá abordar o indivíduo, pois na maioria das vezes, essa abordagem é multidisciplinar e exige que outros profissionais auxiliem não só no tratamento e recuperação, mas em questões emocionais, sociais e econômicas, no objetivo de que a pessoa evite o processo de revitimização e arrete traumas ainda maiores para a mesma $^{(17)}$. 
Alguns municípios, estados e instituições, possuem protocolos específicos para pessoas em situações de violência que devem ser seguidos, pois é um documento que pode ser fundamental na resolução de alguns casos. Quando isso ocorre, o enfermeiro forense é requisitado para testemunhar em tribunal, em que o mesmo irá apresentar com detalhes todos os arquivos e documentos relacionados aos exames e cuidados prestados à vítima, já que alguns processos podem levar anos até chegar à fase de depoimento profissional ${ }^{2}$.

Nesse contexto, têm-se a cadeia de custódia, que funciona como uma garantia a nível judicial que o vestígio recolhido é o mesmo que foi colhido no local do crime, sendo a prova oficial. O resultado deste procedimento é visível em documentos ou formulários elaborados para esse devido efeito, em que identifica os vestígios que foram coletados em determinada data (criando um histórico do percurso), assim como permite identificar todos os indivíduos que os manusearam (desde que foram recolhidos, até ao momento em que foram apresentados em tribunal) ${ }^{(19)}$.

Por meio das falas dos participantes, é imprescindível o treinamento e capacitação dos profissionais da saúde, em especial os enfermeiros, por serem os primeiros a terem o contato direto com as vítimas de violência. Sendo assim, é necessário investir em educação permanente em questões éticolegais, protocolos institucionais, procedimentos técnicos relacionados aos vestígios forenses e a cadeia de custódia no Sistema Único de Saúde (SUS), no intuito de melhorar a qualidade prestada nos serviços de saúde.

Desse modo, as limitações na qualificação profissional para atuar junto às vítimas ainda acontecem em decorrência de uma abordagem incipiente a nível de graduação, pós-graduação e nos próprios serviços de saúde, tanto no aspecto teórico como prático. Por isso, faz-se necessário a realização de projetos extensionistas e/ou de pesquisas em consonância com os serviços que prestam esses atendimentos ${ }^{(17)}$.

\section{CONSIDERAÇÕES FINAIS}

Foi possível compreender como os estudantes de enfermagem relacionaram a enfermagem forense como campo de atuação, trazendo limitações do conhecimento relacionados ao conceito da especialidade e as especificidades de sua prática profiisional, com ênfase na abordagem e cuidado às pessoas em situação de violência e os procedimentos técnicos no manejo de vestígios.

Diante disso, ressalta-se a necessidade emergente da temática ser abordada nos cursos de graduação em enfermagem. Incluíhttps://doi.org/10.31011/reaid-2021-v.95-n.34-art.997 Rev Enferm Atual In Derme v. 95, n. 34, 2021 e-021058 
la como disciplina isolada na matriz curricular, sendo eletiva ou obrigatória, demandaria professores especialistas na área, o que no Brasil são poucos. Em decorrência disso, sugere-se uma reformulação nas ementas das disciplinas que envolvem conteúdos de violência de forma transversal.

Uma das limitações do estudo, foi o recrutamento dos sujeitos participantes da pesquisa, pois os mesmos estavam cumprindo estágio curricular obrigatório, em que houve dificuldades para encontra- los disponíveis na instituição.

Por se tratar de uma especialidade extremamente prática, é essencial que novos estudos possam ser desenvolvidos abordando a área aos estudantes, pois a união de evidências será fundamental para uma futura mudança nos Projetos Pedagógicos dos cursos de graduação em enfermagem.

\section{REFERÊNCIAS}

1. Ghofrani Kelishami F, Manoochehri H, Mohtashami J, Kiani M. Consequences of presence of forensic nurses in health care system: a qualitative study. Iran $\mathbf{J}$ Nurs Midwifery Res. [Internet]. 2020 [acesso em 20 out 2020]. 25(3):195201. Disponível em: https://www.ncbi.nlm.nih.gov/pmc/art icles/PMC7299418/
2. Lynch VA. Forensic nursing science: Global strategies in health and justice. Egypt J Forensic Sci. [internet]. 2011 [acesso em 15 nov 2020]; 1(2):69-76. Disponível em: https://reader.elsevier.com/reader/sd/p ii/S2090536X11000049?token=E92E E76A7FAE16C1B8571981D7AAE38 723EBF497A62FBA90382142D9F14 97EC1D2D1C018C676D6F709448C8 65FB87455

3. Conselho Federal de Enfermagem (Br). Resolução $n^{\circ}$ 389, 18 de outubro de 2011. Procedimentos de título de pós-graduação lato e stricto sensu concedido a enfermeiros e lista as Especialidades [Internet]. Brasília; 2011; [aceso em 29 out 2020] 137(1):119, Disponível em: http://www.cofen.gov.br/resolucaocofen-no-581-2018_64383.html.

4. Conselho Federal de Enfermagem (Br). Resolução $\mathrm{n}^{\circ}$ 556, de 23 de agosto de 2017. Regulamenta a atividade do enfermeiro forense no Brasil [Internet]. Brasília; 2017. [aceso em 29 out 2020] Disponível em:

http://www.cofen.gov.br/resolucaoregulamenta-atuacao-deenfermeiroforense_54193.html

5. Minayo MC de S, Souza ER de, Silva MMA da, ASG de. Institucionalização 
do tema da violência no SUS: avanços

e desafios. Ciênc saúde coletiva.

[Internet] 2018 [acesso em 16 nov 2020]; 23(6): 2007-2016. Disponível em:

https://www.scielo.br/scielo.php?scrip $\mathrm{t}=$ sci_arttext\&pid=S1413-

81232018000602007

6. Cerqueira D, Lima RS, Bueno $\mathrm{S}$, Neme C, Ferreira H, Coelho D, et al. Atlas da Violência 2020 - Ipea e FBSP [Internet]. Brasília: IPEA; 2020 [acesso em 19 nov 2020]. Disponível em:

https://www.ipea.gov.br/atlasviolencia /download/24/atlas-da-violencia-2020

7. Cunha $\mathrm{M}$, Libório $\mathrm{R}$, Coelho $\mathrm{M}$. Knowledge questionnaire over forensics nursing practices. Procedia Soc Behav Sci. [Internet]. 2016; [acesso em 20 out 2020]; 217:108997. Disponível em: https://reader.elsevier.com/reader/sd/p ii/S1877042816001439?token=6FD0 DF1C60B04D1AE398D60E080DF19 EEA1982043ED1667E834B366FE13 799B6411FDA38E0E4B9CC849251E A723F1800

8. Felipe HR, Cunha M, Ribeiro VDS, Zamarioli CM, Santos CBD, Duarte JC, et al. Knowledge Questionnaire over Forensics Nursing Practices: adaptation to Brazil and psychometric properties. Rev Enf Ref .[Internet] 2019 [Acesso em 22 nov 2020]; Série IV(23):99-110.

Disponível: http://www.scielo.mec.pt/pdf/ref/vserI Vn23/serIVn23a11.pdf

9. Bardin L. Análise de Conteúdo. Tradução de Luís Antero Reto e Augusto Pinheiro. São Paulo: Edições 70; 2011. 95-103.

10. Esteves RB, Lasiuk GC, Cardoso L, Kent WA. Toward the establishment of a forensic nursing specialty in Brazil: An integrative literature review. J Forensic Nurs. [Internet] 2014; [acesso em 15 nov 2020]; 10(4):189-98.

11. Kent-Wilkinson A. Forensic nursing educational development: An integrated review of the literature. $\mathrm{J}$ Psychiatr Ment Health Nurs.[Internet] 2011; [acesso em 15 nov 2020]; 18(3):236-46.

12. Baumann R, Stark S. The role of forensic death investigators interacting with the survivors of death by homicide and suicide. J Forensic Nurs. [Internet] 2015 [acesso em 16 nov 2020];11(1):28-32.

13. Mello CMDE, Marin SM. A enfermagem no atendimento em desastres e em eventos com múltiplas vítimas. Vittalle. [Internet]. 2013 [acesso em 17 nov 2020]; 25(1):37-44. 
14. Oliveira MJ, Santos VS, Silva SD, Santos FP, Melo CM. Preservation of forensic traces by health professionals in a hospital in Northeast Brazil. Forensic Sci Int [Internet]. 2019; [acesso em 20 out 2020]; 306:110057. Disponível em: https://linkinghub.elsevier.com/retriev e/pii/S0379073819304694.

15. Camilo LS, Dantas TO, Musse J de O, Silva DP, Assis ES. Preservação da cena de crime pelo enfermeiro no Serviço de atendimento móvel de urgência: uma revisão integrativa. Cad Grad - Ciênc Bio e Saúde - Unit [Internet]. 2017 [acesso em 18 nov 2020]; 4(2):184. Disponível em: https://periodicos.set.edu.br/index.php /cadernobiologicas/article/view/4602/ 2503.

16. Sousa JM, Queiroz PRM. Coleta e preservação de vestígios biológicos para análises criminais por DNA. Ensaios e Ciênc. [Internet] 2012 [acesso em 20 nov 2020]; 16(3): 99115. Disponível em: https://doi.org/10.17921/14156938.2012v16n3p\%25p.

17. Acosta DF, Gomes VLO, Oliveira DC de, Gomes GC, Fonseca AD da. Aspectos éticos e legais no cuidado de enfermagem às vítimas de violência doméstica. Texto contexto - enferm.
[Internet] 2017 [acesso em 20 nov 2020]; 26(3): e6770015. Disponível em:

https://www.scielo.br/pdf/tce/v26n3/0 104-0707-tce-26-03-e6770015.pdf

18. Pereira de Paiva MH, Pinheiro Lages L, Cavalcanti de Medeiros Z, Paiva MHP, Lages LP, De ZC. Studies on forensic nursing in Brazil: a systematic review of the literature. Int Nurs Rev. [Internet] 2016 [acesso em 20 nov 2020]; 64(2): 1-10. DOI: http://dx.doi.org/10.1111/inr.12328

19. Arrais A, Zerbini EC, Jota FSSVB de O, Almeida RR de M, Costa ARC da, Silva KT da. Desafios para implantação da cadeia de custódia para as vítimas de estupro no Distrito Federal. Esc. Anna Nery [internet] 2020 [acesso em 21 nov 2020]; 24(1): e20190101. Disponível em: https://www.scielo.br/pdf/ean/v24n1/p t_1414-8145-ean-24-01e20190101.pdf

Submissão: 2021-01-08

Aprovado: 2021-04-12 